\title{
NAACCR Terminology
}

National Cancer Institute

\section{Source}

National Cancer Institute. NAACCR Terminology. NCI Thesaurus. Code C160911.

Terminology developed to assist the North American Association of Central Cancer Registries with their data standards. 